\title{
CUANDO MATAN LAS MANOS DEL PADRE: LICURGO Y LA FURIA ASESINA
}

\author{
María Cecilia Colombani` \\ Facultad de Filosofías, Ciencias de la Educación \\ y Humanidades - Universidad de Morón \\ Facultad de Humanidades - Universidad Nacional de Mar del Plata
}

RESUMO: O projeto do presente ensaio consiste em indagar as consequências da mania assassina quando Dioniso exerce sua ação sobre homens e mulheres, indistintamente. Até o momento, a presença feminina no palco do horror fica atestada em múltiplos espaços do mito; a figura masculina, ao contrário, se mostra menos ostentosa. O episódio que vamos analisar se situa, precisamente, no enclave masculino como tópos da fúria assassina. Licurgo, rei dos edônios, na Trácia, foi quem proibiu as cerimônias em honra do deus, pelo qual foi castigado. É aqui o local onde Dioniso encontra seu primeiro adversário e ser seu adversário significa sempre o mesmo: não o reconhecer de algum modo, ignorar seu estatuto divino e, portanto, negar ou proibir suas cerimônias, o que desata a fúria do deus. Seu estrangeirismo é a estranheza ontológica de quem rompe a cada instante a tranquila certeza do Mesmo. Daí seu rosto Outro. Daí seu salto carregado de estranha loucura.

PALAVRAS-CHAVE: Mania assassina; horror; filicídio; estranheza; Outridade.

stán aquellos que no lo reconocen y ya lo desconocen: los incrédulos que rechazan creerlo, los atolondrados que afectan considerarlo desdeñable: los agresivos que no quieren oír sus ceremonias. ${ }^{1}$

^ ceciliacolombani@hotmail.com

${ }^{1}$ Cf. Detienne, op. cit., 1986, p. 36. 
El proyecto del presente ensayo consiste en indagar las consecuencias de la manía asesina cuando Dioniso ejerce su acción sobre hombres y mujeres, indistintamente. Hasta el momento, la presencia femenina en el escenario del horror queda atestiguada en múltiples espacios del mito; la figura masculina, en cambio, resulta menos ostentosa.

El episodio que vamos a analizar se sitúa, precisamente, en el enclave masculino como tópos de la furia asesina. Licurgo parece ser uno de aquellos que la cita inaugural refiere. Rey de los edonios, en Tracia, fue quien prohibió las ceremonias en honor del dios, por lo cual fue castigado. Edonia era una zona de la antigua Tracia, situada al este de la Calcídica, entre los ríos Estrimón y Nestus. Es aquí donde Dioniso encuentra su primer adversario y ser su adversario significa siempre lo mismo: no reconocerlo de algún modo, ignorar su estatuto divino y, por ende, negar o prohibir sus ceremonias. Tal como refiere Otto, retomando la versión homérica, "el poderoso Licurgo, hijo de Driante, persiguió en su día a las nodrizas del enloquecido Dioniso por los campos de Nisa, y éstas, tocadas por el arma terrible de Licurgo, arrojaron sus sagrados utensilios al suelo; el propio Dioniso sin embargo se refugió en las honduras del mar, donde Tetis acoge protectora al tembloroso fugitivo".

Licurgo tiene su propio prontuario y ya en Ilíada, Homero se refiere a él como un adversario de los dioses: "Ni siquiera el hijo de Driante, el esforzado Licurgo, que con los celestiales dioses trabó disputa, tuvo vida longeva, el que en otro tiempo a las nodrizas del delirante Dioniso fue acosando por la muy divina región de Nisa" ${ }^{3}$ Licurgo es un desaforado; su conducta hostil lo territorializa al tópos de la desmesura más cruel: "Es un asesino (androphonos) que se arroja sobre las nodrizas de Dioniso el Delirante (Menomenos), dispersa a las portadoras de tirso, persigue al joven dios espantado". ${ }^{4}$ El mismo Homero, que conoce perfectamente a Dioniso y a su cortejo femenino, alude al episodio: "Todas a la vez los tirsos dejaron caer a tierra, por el homicida Licurgo con la aguijada golpeadas".

Esquilo refiere el episodio en los Edonios transitando por los distintos personajes que juegan el drama. Las bacantes, fieles adoradoras

\footnotetext{
${ }^{2}$ Cf. Otto, op. cit., 1997, p. 39.

${ }^{3}$ Homero, Ilíada, VI, 130-134.

${ }^{4}$ Cf. Detienne, op. cit., 1986, p. 37.

${ }^{5}$ Homero, Ilíada, VI, 134-135.
} 
del dios, son encadenadas, el grupo de los sátiros, habituales acompañantes del cortejo dionisíaco, es capturado y hecho prisionero. La saga de Licurgo permite relevar el horrendo sufrimiento de las mujeres seguidoras de Dioniso. Tal como de ello da cuenta el relato que Ilíada ${ }^{6}$ ofrece, las mujeres son perseguidas cruelmente por Licurgo, "que caía con sus terribles armas sobre las mujeres dionisíacas". 7 Esta saga no es más que una muestra de este tópico que retorna con frecuencia en el relato dionisíaco: el maltrato a las mujeres.

El combate entre Dioniso y Licurgo pone a Dioniso en relación con un elemento que configura su identidad como dios, el agua, el elemento líquido. En efecto, para escapar de "la sangrienta persecución que hace huir al mismo dios hacia lejanías inalcanzables", Dioniso debe saltar al mar. Tal como refiere Otto, "el propio dios se habría salvado saltando al mar, de donde es oriundo". " O bien el testimonio directo de Homero cuando narra: "Despavorido, Dioniso se sumergió en el oleaje del mar, y Tetis lo acogió en su regazo, temeroso y presa de violento temblor por las increpaciones del hombre".

Homero remata la saga demostrando, precisamente, lo que significa desconocer la figura de los dioses y el riesgo de ser un teómaco. Licurgo paga también muy caro convertirse en un adversario de los dioses, olvidando la distancia entre hombres y dioses, mortales e inmortales: "Mas pronto abominaron de él los dioses, que pasan fácil la vida, y el hijo de Crono lo dejó ciego. Y ya no duró mucho tiempo, porque se hizo odioso a ojos de todos los inmortales dioses. Tampoco yo estaría dispuesto a luchar con los felices dioses". ${ }^{11}$

Dejemos por el momento el relato homérico. Dioniso no se rinde ante quien lo ofendió; arrastra a Licurgo, como lo hace con Penteo en Bacantes, hasta el extremo mismo de la locura y desata sobre su impiedad la sed de violencia y muerte que acostumbra a desplegar ante sus adversarios. Comienzan entonces los prodigios, que tantas veces acompañan al dios en sus capacidades extraordinarias, esto es, en sus posibilidades que siempre están más allá de lo ordinario, más allá de

\footnotetext{
${ }^{6}$ Homero, Ilíada, VI, 132 ss.

${ }^{7}$ Cf. Otto, op. cit., 1968, p. 143.

${ }^{8}$ Cf. Otto, op. cit., 1968, p. 132.

${ }^{9}$ Cf. Otto, op. cit., 1968, p. 143.

${ }^{10}$ Homero, Ilíada, VI, 135-137.

${ }^{11}$ Homero, Ilíada, VI, 138-141.
} 
todo registro humano; las cadenas que sujetan a las bacantes se sueltan por sí mismas; los muros del palacio real, residencia de Licurgo, oscilan; el techo pierde su calidad de tal y es capturado por el mismo delirio báquico, que no mide ni elige adversarios; su ser se transmuta y se pone a bailar y a saltar como una ménade más. Techo-ménade, como en su momento la propia Tebas se convierte en ménade en el relato euripideo. Todo cae bajo el delirio de un dios que no tolera ni el rechazo ni la indiferencia.

El destino del rey está echado. Entra en estado de posesión báquica y levanta su doble hacha, arma mortal con la que segará la vida de quien más ama. En realidad, su deseo es cortar la viña, el arbusto que el Extranjero ha entrado a su tierra; planta maldita que viene de la mano de quien arrastra a una locura demencial.

Dioniso lo desvía del arbusto y lo acerca hacia su hijo; un niño metamorfoseado en vid que trata de huir despavorido ante la furia asesina de su padre. Una vez más, la metamorfosis, el deslizamiento hacia otra cosa de aquello que uno es; niño-vid como modo de alterar una identidad que pasará a ser la víctima del frenesí asesino. Como en el caso de Penteo ante los ojos de su madre, Ágave, la metamorfosis conduce al no reconocimiento del hijo; Dioniso juega en la misma lógica que padece; utiliza las mismas cartas para jugar un juego del cual no se sale indemne.

Al no reconocimiento de su estatuto regio, responde con una estrategia mortal: el no reconocimiento de aquello que se ama entrañablemente y que jamás, en un estado consciente, podría ser aniquilado. Pura estrategia de un batallador de excelencia.

Licurgo arremete contra el arbusto; corta los sarmientos y el pie de la vid, vale decir, las extremidades de su propio hijo. Dioniso cierra el episodio dándole la muerte, "luego de haber cortado cuidadosamente las extremidades del niño". ${ }^{12}$

Licurgo ha asesinado a su propio hijo y con ello ha asesinado la fertilidad de su tierra, que se ha vuelto estéril, como marca de la impureza cometida. Sabemos también que la impureza mancha, sin distinción de géneros, sujetos y ciudades, familias y linajes. Los edonios deciden, respetando al oráculo de Delfos, conducir a su rey cargado de cadenas en medio de los bosques helados, allí donde se yergue, sobre el monte Pangea, un santuario oracular de Dioniso, donde sus sacerdotisas profetizan, como lo hacen las de Apolo en Delfos, el gran templo que

\footnotetext{
${ }^{12}$ Cf. Detienne, op. cit., 1986, p. 37.
} 
el Señor que reina en Delfos construyera, mostrando su cara de constructor.

El horror no ha culminado aún. La tierra estéril debe ser reparada en su impureza. El propio Dioniso ha determinado que la única forma de purificarla es matando al rey impío. Los edonios no dudan. El rey asesino es conducido por el pueblo al monte Pangeo y despedazado por caballos salvajes; una vez más, la figura del despedazamiento acompaña la dramática dionisíaca.

El sacrificio de Licurgo posibilita que la tierra recobre su fertilidad. Cuatro caballos desmembraron al rey, repitiendo la dramática del sparagmós. Despedazar, desmembrar, seccionar por partes es el destino de las víctimas para que, con ello, se restaure el orden dañado por la impiedad.

\section{Cuando matan las manos de la madre. Las hijas del rey Proitos y la furia asesina}

El proyecto de este segundo apartado del trabajo pretende analizar un nuevo caso de infanticidio a la luz del fenómeno dionisíaco. Se trata del episodio desencadenado con las hijas del rey Proitos, hijo de Abante y de Aglaya. Se trata de un rey de Tirinto evocado por Homero en Ilíada, a propósito del episodio con Belerofontes: "Y por su parte, Glauco engendró al intachable Belerofontes. A éste belleza y amable valentía los dioses le otorgaron. Mas Preto maquinó contra él maldades en el ánimo, porque era muy superior a él, y lo desterró del pueblo de los argivos, a quienes Zeus había sometido al cetro de Preto". ${ }^{14}$ En realidad, el episodio está relacionado con el amor que la esposa del rey siente por Belerofontes. Tal como relata Homero, "[l]a mujer de éste, la divina Antea, concibió enloquecido deseo de unirse a él en secreto amor. Pero no logró convencer los buenos instintos del belicoso Belerofontes". ${ }^{15}$ Antea mintió y le dijo a su marido que Belerofontes había querido unirse amorosamente a ella y ella lo rechazó. Esto llenó de ira al rey, quien eludió matarlo pero "lo envió a Licia y le entregó luctuosos signos, mortíferos la mayoría, que había grabado en una tablilla doble". ${ }^{16}$ Tras

\footnotetext{
${ }^{13}$ Preto o Proitos, hijo de Abante y de Aglaya, es un rey de Tirinto

${ }^{14}$ Homero, Ilíada, VI, 157-160.

${ }^{15}$ Homero, Ilíada, VI, 160-164.

${ }^{16}$ Homero, Ilíada, VI, 168-169.
} 
arduas luchas, Belerofontes, triunfante frente a cada obstáculo, termina casándose con la hija del rey de Licia.

Proitos tiene un hermano gemelo, Acrisio, rey de Argos, con quien mantiene una larga querella, hasta que luego de su muerte, acaba reinando sobre la Argólida.

El rey Proitos tenía tres hijas: Lisipe, Ifianasa e Ifinoé, llamadas las Prétides, o las Proitides, las cuales, al crecer se rehúsan a rendir culto a Dioniso, y enloquecen como tantas otras mujeres, impulsadas a transgredir las reglas que el dionisismo impone. Estamos nuevamente en presencia de un desconocimiento de las pautas que la divinidad impone como forma de reconocer su estatuto divino, el que, por otra parte, se ve, constantemente, puesto en duda o ignorado. Este episodio, por lo tanto, posee una misma matriz de desencadenamiento.

Las mujeres abandonan el palacio paterno y comienzan a vagar erráticas a través del país de Argos. Jean-Pierre Vernant, en el capítulo dedicado a los aspectos míticos de la memoria y del tiempo en su texto Mito y pensamiento en la Grecia Antigua, recoge una leyenda que relata que en las proximidades del Styx se encuentra una gruta donde "las hijas de Proitos se enterraron cuando fueron poseídas del furioso delirio de la manía; es allí donde Melampos vino a arrancarlas para curarlas de su mancha mediante purificaciones de carácter secreto que él les administró en un lugar llamado Lousoi, los baños, en el santuario de Artemisa Hemetrasia, la que apacigua". ${ }^{17}$ El Styx es un río infernal, cargado de un poder de mancha.

Otto compara el destino de las Prétides con el de las Miníades: "Pero aún más: cuando se dice que las Agrionias argivas se celebran en honor de una hija de Preto, no podemos por menos que pensar en la leyenda según la cual las Prétides eran presas de la locura dionisíaca, al igual que las hijas de Minias, siendo por ello perseguidas. En esta persecución encuentra la muerte la mayor de ellas, Ifínoe". ${ }^{18}$

Retornemos a la versión de Detienne. Preocupado ante el destino de sus hijas "Proitos convoca a Melampo adivino y purificador reputado: sus encantamientos, sus hierbas medicinales les devolverían la calma y las purificarían". ${ }^{19}$

Apenas unas palabras de Melampo antes de asumir el final del episodio. Melampo es el primer mortal al que se le confieren poderes

\footnotetext{
${ }^{17}$ Cf. Vernant, op. cit., 2001, p. 132.

${ }^{18}$ Cf. Otto, op. cit., 1968, p. 90.

${ }^{19}$ Cf. Detienne, op. cit., 1986, p. 17.
} 
proféticos y se le considera un pionero en practicar un tipo de saber llamado epameia, el cual se refiere a los cuidados que se le brindan a un enfermo, tal como los actos de culto que se brindan a los dioses. Oficio éste que, más tarde, consistirá en la práctica médica, como aquella particular atención que se le otorga a un enfermo. Melampo sanaba por medios que lo convertían en un iatromantis. Se convierte, así, en un ser excepcional, dotado de poderes extraordinarios, luego de haber pasado por una experiencia de iniciación, que lo sitúa en un lugar intermedio entre el plano de los dioses y el de los hombres. Melampo es uno de los preferidos de Apolo, después de que el dios lo conociera y se le hiciera presente a orillas del río Alfeo.

Volvamos al episodio. El rey Proitos lo convoca y éste, como pago de su trabajo, le pide la tercera parte del reino. El rey se niega ante tamaño pedido, entonces, como es de esperar, el mal empeora; entonces las hijas están progresivamente más y más agitadas, al tiempo que la locura hace presa de toda la población femenina. Por todos los lugares las esposas salen de sus casas, se pierden en el bosque, matan cruelmente a sus hijos. Es así como Melampo obtendrá los dos tercios del reino.

Es la hora de Dioniso y su acción maníaca. La furia dionisíaca comienza a operar con los desplazamientos habituales. Pensemos en dos líneas de análisis.

Una primera línea de análisis se refiere a una dimensión geográfica. Las mujeres abandonan sus casas, tópos habitual de la representación de género; el oikos es el lugar funcional a la identidad femenina porque es el territorio afín a sus cualidades: la atención de la casa, de los maridos y los hijos. De la casa a los bosques, el desplazamiento implica la transgresión del modelo identitario; no se trata solamente de la transgresión de la geografía acordada, sino de la alteración del espacio social y simbólicamente asignado.

El segundo nivel de análisis consiste en pensar la función femenina y allí la transgresión cobra la forma de una alteridad absoluta; del cuidado maternal a la muerte del hijo; de la atención solícita de una madre a las manos asesinas que desconocen el vínculo de filiación constituyente de la identidad femenina. De la nutrición al horror del asesinato, las mujeres de la Argólida transgreden el campo de lo Mismo para entrar en el cono de sombra que la manía arroja como destino áltero: "La locura enviada por Dioniso, su manía, aparece aquí como un mal que ataca a gran número de personas. Tres en primer lugar. Y pronto ninguna será perdonada”. ${ }^{20}$

${ }^{20}$ Cf. Detienne, op. cit., 1986, p. 18. 
Heródoto también refiere al episodio: "En efecto, resulta que, cuando las mujeres de Argos se volvieron locas y los argivos quisieron contratarlo para que acudiera desde Pilos y librase a sus mujeres de la enfermedad, Melampo, por su parte, se avino a hacerlo a cambio de la mitad del reino. Los argivos se negaron a ello y se fueron; pero, en vista de que el número de mujeres que se volvían locas aumentaba, acabaron de transigir ante las pretensiones de Melampo y regresaron dispuestos a concederle lo que pedía".

Independientemente del relato y sus versiones, el dionisismo se presenta como una epidemia, al modo de una enfermedad que se expande y ataca a un gran número de personas, una epidemia de danzas convulsivas, como lo concibe Erwin Rohde. Tal como sostiene Detienne: "Ciertamente la locura dionisíaca lleva en sí un poder de contagio tan grande como la mancha de sangre derramada". 22

La nueva configuración del horror toma las características de una epidemia que se expande. El filicidio se inscribe, pues, en el círculo más amplio de una enfermedad que parece contagiosa.

Hemos avanzado un paso más en la saga dionisíaca; epifanías que descubren el poder decisivo en toda su dimensión; epifanías que devuelven "la locura dura, la manía, que conduce al crimen y a la impureza: viaje al fin de la noche en los pasos enloquecidos de Dioniso". ${ }^{23}$

\section{Cuando matan las manos del compañero. La fatídica construcción de un techo}

El proyecto de este tercer apartado consiste en analizar un nuevo y singular aspecto del horror dionisíaco. El dios no deja de asombrarnos, ni por su errancia y vagabundeo, el que, en esta oportunidad, lo saca de tierras griegas y lo ubica en tierras galas, no habituales para su cosmopolitismo y por la peculiaridad de su comportamiento, que lo ubican, a su vez, en una extraña foraneidad, en una extrañeza sin igual

Es el geógrafo Estrabón el que descubre en tierra foránea, precisamente, en tierra bárbara, un Dioniso de singulares características, que ya había conmovido a Posidonio. Como sabemos, Posidonio fue un geógrafo y filósofo, nacido en Apamea, Siria y que vivió entre 135 y 51 a. C.

\footnotetext{
${ }^{21}$ Heródoto, Historia, IX, 34.

${ }^{22}$ Cf. Detienne, op. cit., 1986, p. 19.

${ }^{23}$ Cf. Detienne, op. cit., 1986, p. 26.
} 
Por su parte, Estrabón, oriundo de Amasia, Ponto, contemporáneo de Augusto, es posterior a Posidonio, vive entre 64 o 63 a. C. hasta los primeros veinte años del siglo I, sin que haya precisión sobre la fecha de su muerte.

Marcel Detienne recoge la observación de Estrabón, que parece coincidir con la del propio Posidonio. Existe en el océano una pequeña isla que ubica en la desembocadura del Loire y que tiene la particularidad de estar habitada exclusivamente por mujeres, las mujeres de los "Namnetos"; mujeres poseídas por Dioniso y encargadas de llevar a cabo distintos ritos para aplacar la ira del dios.

En primer lugar, se repite en tierra gala la misma presencia femenina que parece ser una constante en la saga dionisíaca. Dioniso está siempre acompañado por mujeres, desde su mismo nacimiento, el elemento femenino, sea cual fuese el destino que las mujeres corren, parece constituir una unidad indisoluble con el dios.

En este caso el elemento femenino es tan determinante que ningún varón puede poner pie en la isla. Las mujeres, que tienen esposos, cruzan el agua para unirse a ellos pero para retornar a la isla después. El espacio parece estar clausurado a toda diferencia genérica y la isla es exclusivo patrimonio de las mujeres.

Hasta aquí las marcas de un territorio particular y de cierta conyugalidad, también peculiar. No obstante, no hay rastros aún del horror que, una vez al año, habrá de desatarse, repitiendo las marcas identitarias de un dios que nos tiene acostumbrados a los momentos de máxima tensión en las figuras de la crueldad.

La costumbre es que, anualmente, estas mujeres se pongan en marcha para destruir el techo de un santuario dedicado a Dioniso y lo reemplacen por uno nuevo ese mismo día. La consigna es clara: desmontar y montar, de-construir y reconstruir el mismo día un techo de paja, en honor a un dios, que no suele verse seducido por las obras de arquitectura. Las mujeres deben traer su parte de material y antes de la opuesta del sol lograr el cometido.

El momento del horror se avecina pero no se da en esta oportunidad un crimen de los que conocemos y que suele tener por protagonistas a una madre o a un padre y a un hijo. Si hasta ahora hemos visto que la sangre vertida implicaba miembros que guardaban lazos de parentesco, ahora la sangre toma cuerpo comunitario.

Aquella mujer cuyo fardo cae al suelo, en el momento de estar cumpliendo con las tareas ritualizadas, es despedazada por sus compañeras, que, alborotadas, se pasean llevando los pedazos alrededor 
del santuario pronunciando el evohe, como signo característico de la posesión; acción que no cesa hasta que su delirio llegue a su fin.

La conducta es por demás singular; el viejo despedazamiento, sparagmós, ponía en juego un vínculo familiar que tensionaba las relaciones parentales y maternales, sobre todo éstas últimas, con la peculiaridad agregada de ser habitualmente tres las mujeres que juegan el drama trágico: Ágave y sus dos hermanas, las Miníades, las Prétides, parecen responder a un mismo modelo de acción y a un mismo núcleo de desconocimiento. Mujeres pertenecientes a un espacio de poder, hijas de un rey, ya sea Penteo, Minias o el rey Preto, todas conocen una casa regia.

Como sabemos y hemos analizado, las marcas del desconocimiento llevan a estas mujeres posesas a ultimar el despedazamiento de la pieza más amada, el hijo.

En esta oportunidad, se rompe el esquema familiar y soberano que sostiene el drama y genera consecuencias sobre los actores del drama, pero también sobre las casas reales, y las manos asesinas recaen sobre un par, una compañera del colectivo, una más de las mujeres que habitan la isla, pareciendo constituir una comunidad femenina.

Más allá de las precisiones que Detienne busca en torno al lugar de la práctica, sus rasgos siguen siendo muy helénicos y Dioniso sigue siendo Dioniso más allá de la tierra de su arribo. Tal como el mismo Detienne sostiene: "Por lo tanto, un Dioniso entre tierra y mar; un dios insular, aparentemente el único amo a bordo. En torno a él, una congregación de damas nantesas, dedicadas a su servicio; exclusivo, pues ningún varón puede llegar ni residir en la isla, como si toda entera estuviese consagrada a un dios más misandrógino aún que si fuese misántropo". ${ }^{24}$

Un rasgo interesante es la exclusividad a la que alude la cita. Veníamos transitando relatos donde la locura era el punto de fuga de una vida consagrada a tareas, familiares, domésticas y conyugales, como marcas de género dominantes. No es éste el escenario que devuelve este nuevo esquema epifánico. Las mujeres están íntegramente dedicadas a quien parece ser su amo, desterritorializadas del dispositivo de género habitual. Apenas una visita a sus maridos, apenas una escapa a tierra firme, que el propio Señor autoriza con regreso pautado. "Fuera de este permiso, las poseídas de la isla están enteramente ocupadas en el servicio de Dioniso y consagradas a conciliarse con su dios en las abundantes liturgias". ${ }^{25}$ Creemos ver en la absoluta consagración de las

\footnotetext{
${ }^{24}$ Cf. Detienne, op. cit., 1986, p. 89.

${ }^{25}$ Cf. Detienne, op. cit., 1986, p. 90.
} 
mujeres un punto de ligazón con el tema del reconocimiento, que ha sido un pilar en nuestras interpretaciones del fenómeno dionisíaco.

La entrega absoluta, la devoción sin límites, el abandono de cualquier tarea que desvíe el cuidado y la entrega al dios, es el eterno y permanente reconocimiento de la divinidad; la comunidad enteramente cerrada, obturada a cualquier presencia no iniciada, habla de la certeza absoluta de la fidelidad y del reconocimiento como matriz de convivencia.

Dioniso se muestra como un verdadero amo, ejerciendo un poder absoluto sobre sus posesas. Es él quien regula el calendario conyugal, el que dona los permisos, las entradas y las salidas, y, sobre todo, el que vela por la cohesión de su isla. Pareciera darse esa comunión a la que alude Louis Gernet cuando habla de Dioniso como un dios más palpable, en contraposición a Apolo, el señor muy alto que reina en Delfos. Esa palpabilidad parece achicar la brecha entre mortales e inmortales y la isla parece consumar el sueño de la proximidad. ${ }^{26}$

Es en nombre de esa misma soberanía donde poder y terribilidad concilian sus rangos. El poder se vuelve terrible y las órdenes del Señor desatan la crueldad. Una vez por año, el dios exige que se renueve su techo. Extraña conducta de un Dioniso poco afecto a las grandes construcciones, a los templos de gran envergadura, desvelo de Apolo, el gran arquitecto. ${ }^{27}$

El dios quiere un techo nuevo y sus posesas saben satisfacerlo, aunque con ello se pierda la tranquilidad de la isla y la vida de un par: "Sin perder un instante, cada una toma su carga, y es entonces que, cada año, infaltablemente, ocurre un accidente. En el curso de la maniobra, hay siempre una Dama de Dioniso que deja caer su fardo y que se cae

${ }^{26}$ Cf. Gernet, op. cit., 1981 (cap. I). En este capítulo Gernet alude a las dos razas o mundos impermeables entre sí que el plano humano y el plano divino determinan en su diferencia ontológica. Más allá de tal brecha, Gernet postula un doble movimiento, uno de aproximación y otro de asimilación, como formas de achicar la distancia. Es en este marco donde Dioniso, presente entre sus fieles, a partir de sus peculiares modos de aparición, se revela como un dios más palpable.

${ }^{27}$ Sobre este punto, basta pensar en la propia obra de Marcel Detienne, Apolo con el cuchillo en la mano, donde, en su primer capítulo, hace un magistral análisis del Apolo constructor, siguiendo el itinerario que el Himno Homérico a Apolo devuelve. Apolo arquitecto, Apolo constructor, el señor de Delfos termina construyendo un gran templo. De Delos a Delfos, la tarea del constructor habla de su rol civilizador del espacio y de su gusto por la construcción. 
ella misma”. ${ }^{28}$ Este es el comienzo del fin. Una caída, una aparente y trivial caída, que podría pasar por un simple accidente laboral.

Lo que sobreviene pone a Dioniso en el lugar familiar del desencadenamiento trágico. De la simple caída al despedazamiento, la clave parece estar en el gesto mismo de la caída. En este contexto, un tropezón sí es caída porque el tropezón, como trampa mortal, signa el destino de la desgraciada.

El tropezón trae consigo las marcas del dionisismo y las evocaciones de otros episodios. Comienza a darse lo que podríamos llamar un cierto isomorfismo estructural, ya que estas mujeres insulares, próximas a su señor y devotamente entregadas a su servicio en una isla de absoluta privacidad, toman repentinamente las marcas de las Miníades, las Prétides o la misma Ágave; no hay distancia, más allá de las diferencias que trabajamos en párrafos precedentes, en este punto específico en que se desata la furia asesina.

Dos cuestiones llaman la atención de Marcel Detienne en el texto que estamos comentando. En primer lugar, un deseo extraño al propio dios de tener un techo nuevo, que debe ser acabado en un plazo exiguo; en segundo lugar, el detalle de la caída como nota determinante de la manía asesina.

Si pensamos en el primer interrogante, pareciera modificarse la marca nomádica de Dioniso, la cual ha sido un hito en la construcción identitaria que el propio Detienne hace del dios: su nomadismo, su vagabundeo, su cosmopolitismo, su errancia por tierras conocidas y desconocidas, parecen estar lejos del deseo de tener un templo cuyo techo es anualmente desmontado para volverse a montar. Lo conocemos desde otra faceta: "Se lo ve, en efecto, ir de una morada a otra, de una simple casa a un santuario modesto". ${ }^{29}$ No obstante, parece que el Señor quiere un techo, un techo de hechura femenina. Detienne se pregunta si será un capricho o una fantasía.

Nuestra interpretación transita por el polimorfismo de Dioniso, por las múltiples máscaras de este dios que, por esto mismo, fascinara a otro artista de las máscaras: Nietzsche. Dioniso es uno y muchos; su multiplicidad ontológica no se agota en una única marca identitaria; su ser está siempre en fuga, desterritorializándose de los signos unívocos y definitivos. Hoy prefiere una morada modesta, pero, ese continuo reinventarse como dios lo lleva, mañana, a desear un techo nuevo cada

\footnotetext{
${ }^{28}$ Cf. Detienne, op. cit., 1986, p. 90.

${ }^{29}$ Cf. Detienne, op. cit., 1986, p. 92.
} 
año. No sabemos si se trata de un capricho o de una fantasía, en términos de Detienne. Optamos, más bien, por la línea interpretativa que presentamos y por una interpretación relacionada al poder. El poder de la divinidad es insondable; se trata de un ejercicio que no rinde cuentas ni tiene porqué justificarse.

Dioniso puede desear un techo nuevo y obra y exige en consecuencia.

¿Y el tropezón? ¿Qué pasa con esta caída desencadenante de la manía más álgida, aquella que conduce a la muerte y emparienta, sin distinción, al colectivo femenino en su conjunto en el mismo punto de coincidencia asesina? En este punto, el análisis de Detienne, con el que coincidimos, pasa por la importancia del pie en el dispositivo dionisíaco; el pie, el salto, la pierna, como partes esenciales del cuerpo dionisíaco. La elevación del pie, la postura de la pierna, la elevación de la misma, el pie lanzado hacia adelante hablan de un gestualidad anatómica convertida en ritualidad. Tal como sostiene Detienne: $<$ A través de Dioniso saltarín, el pie (pous) encuentra el verbo saltar (pèdan) y su forma "saltar lejos de" (ekpèdan) que es un término técnico del trance dionisíaco: cuando la pulsión del salto invade el cuerpo, lo arranca a sí mismo y lo arrastra irresistiblemente. $>^{30}$ He aquí la clave del desenlace trágico. La caída pone en marcha el dispositivo dionisíaco. El tropezón y la caída marcan el inicio de esa anatomía ritualizada que abre el escenario menádico: "[E]l trance dionisíaco comienza por el pie, con el salto, primer aspecto del pie en el dominio de Dioniso". ${ }^{31}$

La gestualidad parece identificar esencialmente al dios y a sus fieles; es el pasaporte a una instancia áltera que, abruptamente, fractura lo cotidiano, pero que, a su vez, los reúne en un ritual que, esencialmente, los convierte en una unidad, la unidad privilegiada de una absoluta pertenencia sustancial.

Tantos techos temblaron ante la presencia del Extranjero; tantas paredes parecieron resquebrajarse ante la epifanía del extraño extranjero, que ahora su deseo es deshacer y reconstruir un techo; su thíasos lo satisface, al tiempo que padece un nuevo episodio de su locura frenética; episodio abrupto, desconcertante, fracturante de toda certeza, áltero como es siempre áltera su singularidad. Un episodio que lo territorializa a esa foránea Otredad que suele acompañarlo.

\footnotetext{
${ }^{30}$ Cf. Detienne, op. cit., 1986, p. 95.

${ }^{31}$ Cf. Detienne, op. cit., 1986, p. 96.
} 
Tal como sostiene Detienne, resumiendo el episodio: "El Dioniso de las mujeres enloquecidas, en delirio, y que llevan en las manos no ya los materiales de un trabajo improvisado, efímero, sino los miembros palpitantes de una mujer descuartizada bajo la mirada de un dios terrible que hace reventar un cuerpo al azar. Al azar irresistible de un fragmento de cielo abierto en un techo". ${ }^{32}$ Un nuevo punto de contacto con análisis precedentes. Las manos que matan son ahora las manos de un par, pero, a la base, el mismo desplazamiento ontológico que la manía reporta.

Las mujeres han olvidado su lugar en la isla, la camaradería que, en cierto sentido, las convertía en ese colectivo exclusivo de servicio a Dioniso, su pertenencia a un espacio de relación privilegiada con su dios. Ya no son las manos asesinas de una madre o una tía que completan un infanticidio bajo la posesión que la manía arrastra, pero sí son manos asesinas. De los trabajos y los días a la sangre vertida en el suelo familiar. De la tarea constructiva de desmontar y montar un techo en el plazo que el Señor indica, a la configuración de una identidad asesina, destructora de quien minutos antes era un par. Lo que determina la brutalidad de la transformación es, como siempre, el trastocamiento ontológico que el estado de posesión implica.

Las mujeres laboriosas se convierten en esta Otredad asesina, en un nuevo acto de desconocimiento. Aquella que trastabilla deja de ser reconocida como una más dentro del colectivo. Ha perdido a los ojos y las manos asesinas su calidad de semejante. Es pura presa a despedazar.

Pero esto no es más que un nuevo escenario dionisíaco. No nos asombremos demasiado. Es, en algún punto, más de lo mismo. Es apenas un simulacro, una máscara del enfant terrible. Si durante un año entero, parece mostrarnos su rostro más prudente, un día estalla en su terribilidad acostumbrada, en esa crueldad que lo convierte en "el Extranjero del interior, el dios que trata a cada uno a sangre y fuego a su antojo". 33

No dudemos. Su extranjería es la extrañeza ontológica de quien rompe a cada instante la tranquila certeza de lo Mismo. De allí su rostro Otro. De allí su salto cargado de extraña locura.

\footnotetext{
${ }^{32}$ Cf. Detienne, op. cit., 1986, p. 103.

${ }^{33}$ Cf. Detienne, op. cit., 1986, p. 104.
} 


\section{Referencias}

BERMEJO BARRERA, J. C.; GONZÁLEZ GARCÍA, F. J.; REBOREDA MORILLO, S. Los orígenes de la mitología griega. Madrid: Akal, 1996.

DETIENNE, M. Dioniso a cielo abierto. Trad. Margarita Mizrahi. Barcelona: Gedisa, 1986.

DETIENNE, M. Apolo con el cuchillo en la mano: una aproximación experimental al politeísmo griego. Trad. Mar Llinares García. Madrid: Akal, 2001.

DODDS, E. R. The Greeks and the irrational. Berkeley: University of California Press, 1964.

GERNET, L. Antropología de la Grecia Antigua. Trad. B. Moreno. Madrid: Taurus, 1981.

GERNET, L.; BOULANGER, A. El genio griego en la religión. Trad. Serafín Agud y José María Díaz-Regañón López. México: Uteha, 1960.

HERÓDOTO. Historia. Trad. Carlos Schrader. Madrid: Gredos, 2000.

HOMERO. Ilíada. Trad. Emilio Crespo Guemes. Madrid: Gredos, 2000.

NILSSON, M. P. Historia de la religiosidad griega. Trad. Martín Sánchez Ruipérez. Madrid: Gredos, 1969.

OTTO, W. Teofanía. Trad. Juan J. Thomas. Buenos Aires: Eudeba, 1968.

OTTO, W. Dioniso: mito y culto. Trad. Cristina García Ohlrich. Madrid: Ediciones Siruela, 1997.

VERNANT, J. P. La muerte en los ojos. Trad. Daniel Zadunaisky. Barcelona: Gedisa, 1986.

VERNANT, J. P. Mito y pensamiento en la Grecia Antigua. Trad. Juan Diego López Bonillo. Barcelona: Ariel, 2001. 